\title{
DERMATOLOGIC HISTORY
}

\section{Ken Hashimoto - A Pioneer in Dermatological Electron Microscopy}

Reem Kashlan, $\mathrm{MPH}^{1}$, Joshua M. Brady, BS ${ }^{1}$, Meena Moossavi, MD, MPH${ }^{1}$

${ }^{1}$ Wayne State University School of Medicine

Ken Hashimoto was born in Niigata, Japan on June 19, 1931. Hashimoto, a Fulbright scholar, received his medical degree from Niigata University Medical School and dermatological training at the University of Maryland and Massachusetts General Hospital. ${ }^{1}$ Hashimoto subsequently established and was chair of the Dermatology program at Wright State University before coming to Wayne State University (WSU) in 1980. ${ }^{1,2}$ Hashimoto held his position as Professor and Chairman of WSU until his retirement in 2000 , becoming the first and only Japanese national to head an American dermatological department at that time. ${ }^{1}$

Hashimoto's proficiency with the electron microscope and extensive knowledge of histochemistry was vital to the understanding of many diseases. One of the most important applications of his skills was an electron microscopy study outlining the specific dermatological histopathology of angiokeratoma corporis diffusum, also known as Fabry disease. ${ }^{2} \mathrm{He}$ further utilized his skills to expand on many other dermatological pathologies such as Kaposi's sarcoma and appendage tumors of the skin. ${ }^{1}$ Notably, Hashimoto was involved with the discovery of two rare dermatological diseases: transient bullous dermolysis of the newborn and congenital self-healing reticulohistiocytosis, also known as Hashimoto-Pritzker disease. ${ }^{1}$

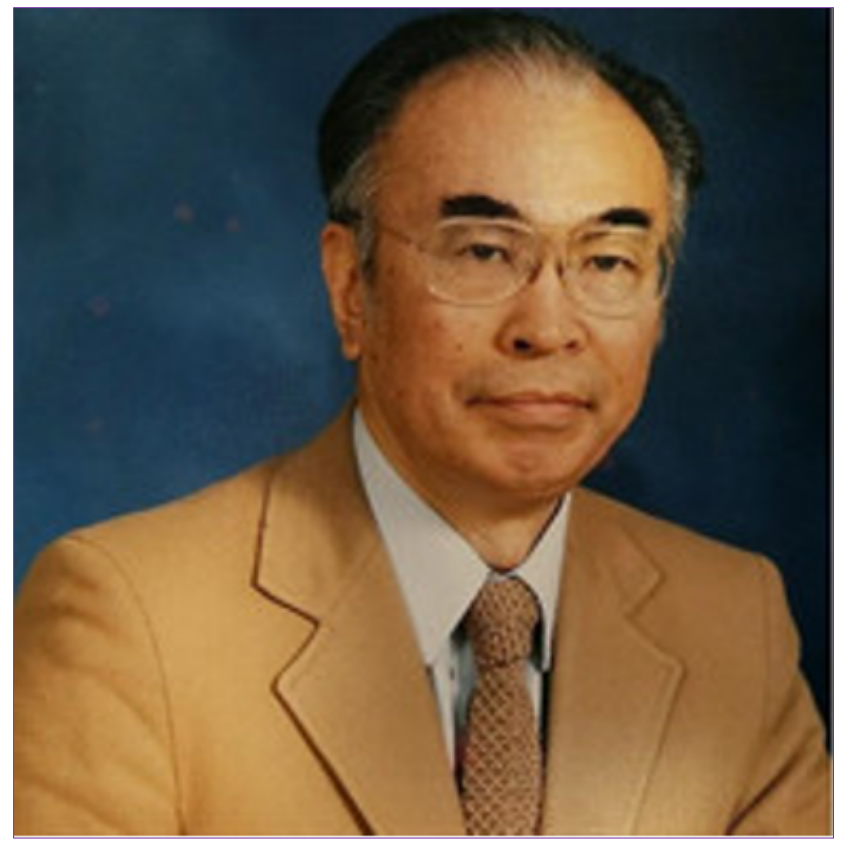

During his academic career, Hashimoto wrote 384 professional papers, 39 book chapters, and 8 books. ${ }^{3}$ As a professor and program director, Hashimoto excelled as a mentor, training 100 resident physicians and 40 research fellows. ${ }^{3} \mathrm{He}$ also focused his efforts on easing the transition of Japanese dermatology students coming to the United 
States for postgraduate training. ${ }^{1}$ Prior to his retirement, Hashimoto created the Herman Pinkus Endowed Chair in 1999, which allowed the WSU Department of Dermatology to remain an independent department. In 2007, Ken Hashimoto and his wife established the Dr. Ken Hashimoto and Noriko Hashimoto Endowed Chair at WSU to promote research and ensure a lasting legacy of education. ${ }^{3}$ Hashimoto's countless contributions left a lasting impression on the field of dermatology, where his academic achievements will continue to impact future generations of dermatologists.

Conflict of Interest Disclosures: None

Funding: None

Corresponding Author:

Reem Kashlan, MPH

540 E. Canfield Ave, Detroit, MI, 48201

Phone: 248-410-3289

Email: reem.kaslan2@med.wayne.edu

References:

1. Crissey JT, Parish LC, Holubar K. Chapter 17: Recent Times. In: Historical Atlas of Dermatology and Dermatologists. Parthenon Pub. Group; 2002:179-180.

2. Hashimoto K, Gross BG, Lever WF.

Angiokeratoma Corporis Diffusum (Fabry). Histochemical and Electron Microscopic Studies of the Skin. J Invest Dermatol. 1965;44:119-128. http://www.ncbi.nlm.nih.gov/pubmed/14258908. Accessed September 25, 2019.

3. Former Dermatology Department chair's bequest creates endowed chair - School of Medicine News - Wayne State University. https://today.wayne.edu/medicine/news/2008/10/ 08/former-dermatology-department-chairsbequest-creates-endowed-chair-25192. Published 10/08/2008. 